\title{
ANTIOKSIDAN KUMARIN TERISOPRENILASI DAN ALKALOID INDOL DARI KULIT BATANG Zanthoxylum ovalifolium Tutcher
}

\author{
Sisca Noviana Nur Khasanah, Nur Imaniah, Ratih Dewi Saputri, Tjitjik Srie Tjahjandarie, Mulyadi Tanjung* \\ Lab. Kimia Organik Bahan Alam, Departemen Kimia, Fakultas Sains dan Teknologi, \\ Universitas Airlangga, Surabaya 60115, Indonesia \\ *corresponding Author : mulyadi-t@fst.unair.ac.id
}

\begin{abstract}
Two isoprenylated coumarins, imperatorin (1), isopimpinelin (2) and one indol alkaloid compound, canthine-6-one (3) were isolated from the stem bark of Zanthoxylum ovalifolium Tutcher. Their structures were determined based on spectroscopic data such as UV, IR, MS and NMR. Imperatorin (1) showed high activity inhibition DPPH radical, isopimpinelin (2) and chantine-6-one (3) has moderate activity.
\end{abstract}

Keywords: Zanthoxylum ovalifolium, coumarin, alkaloid, antioxidant

\section{PENDAHULUAN}

Zanthoxylum ovalifolium Tutcher merupakan salah satu spesies dari famili Rutaceae. Secara tradisional, tumbuhan ini dimanfaatkan masyarakat sebagai obat penurun panas, dan diuretika [1]. Zanthoxylum menghasilkan senyawa alkaloid, kumarin, terpenoid, flavonoid, steroid dan lignan [2].

Dalam rangka penelitian fitokimia senyawa kumarin terisoprenilasi dan alkaloid dari $Z$. ovalifolium tumbuhan Indonesia. Pada kesempatan kali ini akan dilaporkan penemuan dua senyawa kumarin terisoprenilasi yakni imperatorin (1), isopimpinelin (2) dan satu senyawa alkaloid indol yakni kantin-6-on (3) dari kulit batang $Z$. ovalifolium. Selain itu juga akan dilaporkan aktivitas antioksidan ketiga senyawa terhadap radikal DPPH.

\section{METODE PENELITIAN \\ Prosedur Umum}

Spektrum UV ditetapkan dengan spektrofotometer UV-Vis Shimadzu 1800. Spektrum IR ditentukan dengan spektrofotometer IR Perkin Elmer menggunakan pelet $\mathrm{KBr}$. Spektrum massa ditentukan dengan spektrometer HR-ESI-MS merck Waters LCT XE ESI. Spektrum NMR ditentukan dengan spektrometer NMR JEOL ECA 400 yang beroperasi pada 400 $\mathrm{MHz}$ yang beroperasi pada $400 \mathrm{MHz}\left({ }^{1} \mathrm{H}-\mathrm{NMR}\right)$ dan $100 \mathrm{MHz}\left({ }^{13} \mathrm{C}-\mathrm{NMR}\right)$ menggunakan pelarut. Kromatografi kolom gravitasi menggunakan silika gel 60 Merck (artikel no. 1.0774931.1000), kromatografi radial menggunakan silika gel 60 $\mathrm{PF}_{254}$ (Merck) dan kromatografi lapis tipis kromatografi lapis tipis (KLT) menggunakan plat
KLT silika gel $60 \mathrm{GF}_{254} 0.25 \mathrm{~mm}$ (Merck) dan penampak noda menggunakan pereaksi serium sulfat.

\section{Bahan tumbuhan}

Kulit batang Z. ovalifolium diperoleh dari Gunung Salak, Bogor, Jawa Barat. Spesimen tumbuhan diidentifikasi di Herbarium bogorienses dengan nomor voucher 65790 , Lembaga Ilmu Pengetahuan Indonesia (LIPI) Biologi, Cibinong, Bogor, Jawa Barat.

\section{Ekstraksi dan isolasi kumarin terisoprenilasi dan alkaloid indol}

Ekstraksi kulit batang Z. ovalifolium sebanyak 2,5 $\mathrm{kg}$ menggunakan metanol pada suhu kamar sebanyak dua kali selama 24 jam. Ekstrak metanol yang diperoleh dipekatkan dengan alat penguap bertekanan rendah sehingga diperoleh ekstrak kental metanol berwarna coklat $(97 \mathrm{~g})$. Ekstrak metanol selanjutnya dipartisi dengan $n$-heksana menghasilkan ekstrak nheksana (28 g) dan ekstrak metanol (125 g). Ekstrak metanol selanjutnya ditambahkan asam sulfat 5\% pH 3-4 kemudian dipartisi dengan etil asetat menghasilkan ekstrak etil asetat dan fasa asam. Ekstrak etil asetat (senyawa non alkaloid) dipekatkan dengan alat penguap bertekanan rendah menghasilkan ekstrak kental coklat sebanyak 20 g. Fasa asam ditambahkan ammoniak $\mathrm{NH}_{4} \mathrm{OH}$ pekat sampai $\mathrm{pH}$ 8-9 untuk mengubah garam alkaloid menjadi alkaloid bebas [3]. Ekstraksi fasa basa dipartisi etil asetat menggunakan corong pisah menghasilkan ekstrak kasar alkaloid sebanyak 2,5 g. Pemisahan ekstrak etil asetat (19 g) dengan kolom 
kromatografi gravitasi menggunakan campuran eluen $n$-heksana:etil asetat $(9: 1,8: 2$, dan 1:1) menghasilkan empat fraksi utama A-D. Berdasarkan analisis KLT, fraksi D memperlihatkan pendaran warna ungu dengan lampu UV $\lambda_{\text {maks }} 254 \mathrm{~nm}$ yang khs untuk senyawa kumarin Pemisahan fraksi $\mathrm{D}$ dengan kromatografi kolom tekan dengan eluen $n$ heksana:etilasetat (9:1 sampai 7:3) menghasilkan lima subfraksi $\mathrm{D}_{1}-\mathrm{D}_{5}$. Pemurnian subfraksi $\mathrm{D}_{1}$ dilakukan dengan sephadex dan kromatografi radial dengan menggunakan eluen $n$ heksana:etilasetat (9:1 sampai 1:1) menghasilkan senyawa imperatorin (1) sebanyak 46,5 mg. Dari<smiles>CC(C)=CCOc1c2occc2cc2ccc(=O)oc12</smiles><smiles>O=c1ccc2nccc3c4ccccc4n1c23</smiles>

(3) subfraksi yang sama didapatkan senyawa isopimpinellin (2) sebanyak $25,6 \mathrm{mg}$.

Pemisahan ekstrak alkaloid $(2,0 \quad \mathrm{~g})$ menggunakan kolom kromatografi gravitasi dengan campuran eluen heksana:etilasetat (9:1 sampai 1:1) menghasilkan lima fraksi utama A-E. Berdasarkan analisis KLT, fraksi $\mathrm{E}$ memperlihatkan spot berwarna coklat kemerahan dengan pereaksi Dragendorf [4]. Pemurnian fraksi E (189 mg) yang mengandung senyawa alkaloid menggunakan kromatografi radial dengan campuran eluen $n$-heksana:kloroform (9:1 sampai 7:3), kloroform, dan kloroform:etil asetat (9:1 hingga 8:2) menghasilkan senyawa kantin-6-on (3) sebanyak 14,9 mg.<smiles>COc1c2ccc(=O)oc2c(OC)c2ccoc12</smiles>

(2)

Gambar 1. Struktur imperatorin (1), isopimpinellin (2) dan kantin-6-on (3)

\section{Uji aktivitas antioksidan terhadap radikal DPPH}

Penentuan uji aktivitas antioksidan senyawa 1-3 terhadap radikal DPPH menggunakan metode spektrometri secara in vitro [5-7]. Penentuan aktivitas antioksidan dilakukan dengan melarutkan masing-masing senyawa hasil isolasi dengan metanol dalam 2500 $\mu \mathrm{g} / \mathrm{ml}(100 \mu \mathrm{L})$ kemudian ditambahkan larutan buffer asetat $0,1 \mathrm{M}(\mathrm{pH} 5,5)(100 \mu \mathrm{L})$ dan ditambahkan larutan radikal DPPH $\left(5 \times 10^{-4} \mathrm{M}, 50\right.$ $\mu \mathrm{L})$ menghasilkan larutan uji $1000 \mu \mathrm{g} / \mathrm{ml}$. Variasi konsentrasi larutan uji $(1000 ; 500 ; 250$; $100 ; 50 \mathrm{dan} 10 \mu \mathrm{g} / \mathrm{ml})$. Asam askorbat digunakan sebagai kontrol positif [8]. Larutan DPPH $\left(10^{-4}\right.$ M) sebagai larutan pembanding dibuat dengan cara menambahkan metanol $(100 \mu \mathrm{L})$, larutan buffer asetat $(100 \mu \mathrm{L})$ ke dalam larutan DPPH $\left(5 \times 10^{-4} \mathrm{M}, 50 \mu \mathrm{L}\right)$. Penentuan daya hambat senyawa hasil isolasi terhadap radikal DPPH diamati dengan menggunakan spektrometer pada $\lambda 517 \mathrm{~nm}$ setelah diinkubasi selama 30 menit pada suhu $20^{\circ} \mathrm{C}$. Nilai $\mathrm{IC}_{50}$ dapat dihitung melalui ektrapolasi garis $50 \%$ serapan senyawa uji terhadap berbagai konsentrasi menggunakan analisis regresi.

\section{HASIL DAN PEMBAHASAN}

Dua senyawa kumarin terisoprenilasi yakni imperatorin (1), isopimpinelin (2) dan satu alkaloid indol yakni kantin-6-on (3) telah berhasil dipisahkan dari kulit batang Zanthoxylum ovalifolium Tutcher.

Imperatorin (1) berwujud padatan kuning muda dengan titik leleh t.1.101-102 ${ }^{\circ}$ C. Spektrum HRESIMS memperlihatkan ion kuasimolekul positif $[\mathrm{M}+\mathrm{H}]^{+}$pada $m / z 271,0911$ yang sesuai dengan rumus molekul $\mathrm{C}_{16} \mathrm{H}_{15} \mathrm{O}_{4}$. Spektrum UV 
senyawa 1 dalam $\mathrm{MeOH}$ memperlihatkan serapan maksimum pada $\lambda$ maks $(\log \varepsilon): 217(4,19) ; 242$ $(4,05) ; 263(3,86) ; 299(3,83)$ yang merupakan ciri khas senyawa kumarin [9]. Spektrum IR senyawa 1 dalam $\mathrm{KBr}$ memperlihatkan pita serapan pada $v_{\text {maks }}: 1720 \quad(\mathrm{C}=\mathrm{O}$ lakton terkonyugasi), $1706(\mathrm{C}=\mathrm{C}$ alkena), 1585-1487 $(\mathrm{C}=\mathrm{C}$ aromatik) dan 1149 (eter) [10]. Spektrum ${ }^{1} \mathrm{H}-\mathrm{NMR}$ (400 MHz, Tabel-1) senyawa 1 dalam $\mathrm{CDCl}_{3}$ memperlihatkan sepasang sinyal doublet dari cis vinilik $(J=9,6 \mathrm{~Hz})$ pada $\delta_{\mathrm{H}} 7,75(\mathrm{H}-4)$ dan 6,34 (H-3) serta satu sinyal singlet aromatik $\delta_{\mathrm{H}} \quad 7,34(\mathrm{H}-5)$ yang khas untuk kumarin trisubstitusi. Sepasang sinyal doublet $(J=2,2 \mathrm{~Hz})$ pada $\delta_{\mathrm{H}} 7,67(\mathrm{H}-2$ ') dan 6,79 (H-3') merupakan sinyal proton dari cincin furo [11]. Spektrum ${ }^{1} \mathrm{H}-$ NMR senyawa 1 memperlihatkan sinyal proton $O$-terisoprenilasi pada $\delta_{\mathrm{H}} 4,98(2 \mathrm{H}, d, J=7,2$ $\left.\mathrm{Hz}, \mathrm{H}-1^{\prime \prime}\right), 5,59\left(1 \mathrm{H}, t, J=6,2 \mathrm{~Hz}, \mathrm{H}-2^{\prime \prime}\right), 1,72$ $\left(3 \mathrm{H}, s, \mathrm{H}-4^{\prime \prime}\right)$ dan 1,69 (3H, s, H-5') . Spektrum ${ }^{13} \mathrm{C}-\mathrm{NMR}$ (percobaan APT, $100 \mathrm{MHz}$, Tabel-1) senyawa 1 dalam memperlihatkan 16 sinyal atom karbon yang terpisah secara sempurna dan posisi karbon telah dikonfirmasikan dengan spektrum HMQC dan HMBC. Penempatan cincin furo dan $O$-terisoprenilasi ditetapkan berdasarkan analisis spektrum HMQC dan HMBC. Berdasarkan analisis spektrum HMBC (Tabel-1), sinyal proton cis vinilik pada $\delta_{\mathrm{H}}$ 7,75 (H-4) memperlihatkan korelasi dengan satu sinyal karbon oksiaril pada
$\delta_{\mathrm{C}} 143,8$ (C-9), satu sinyal karbon karbonil lakton pada $\delta_{\mathrm{C}} 160,6(\mathrm{C}-2)$ dan satu sinyal karbon metin pada $\delta_{\mathrm{C}} 113,2$ (C-5). Hasil korelasi ini menunjukkan pada inti aromatik C-5 tidak mempunyai substituen. Sinyal proton singlet aromatik $\delta_{\mathrm{H}}$ 7,34 (H-5) berkorelasi dengan dua sinyal karbon oksiaril pada $\delta_{\mathrm{C}} \delta_{\mathrm{C}} 148,6$ (C-7) dan $\delta_{\mathrm{C}} 143,8$ (C-9) serta satu sinyal karbon metin pada $\delta_{\mathrm{C}} 106,8$ (C-3'). Hasil korelasi ini menempatkan cincin furo terhubungkan di C-6 dan C-7 inti aromatik. Sinyal proton singlet cincin furo pada $\delta_{\mathrm{H}} 6,79(\mathrm{H}-3$ ') berkorelasi dengan sinyal karbon oksiaril pada $\delta_{\mathrm{C}} 148,6$ (C-7), satu sinyal karbon kuarterner pada $\delta_{\mathrm{C}} 125,9(\mathrm{C}-6)$ dan satu sinyal karbon metin pada $\delta_{\mathrm{C}} 146,7$ (C2 "). Hasil korelasi ini mempertegas cincin furo terhubungkan di C-6 dan C-7. Sinyal proton metilen dari $O$-terisoprenilasi pada $\delta_{\mathrm{H}} 4,98(\mathrm{H}-1$ '”) memperlihatkan korelasi dengan satu sinyal karbon oksiaril pada $\delta_{\mathrm{C}} 131,6$ (C-6), satu sinyal karbon kuarterner pada $\delta_{\mathrm{C}} 139,8$ (C-2'") dan satu sinyal karbon metin pada $\delta_{\mathrm{C}} 119,8$ (C-2'"). Hasil korelasi ini menunjukkan bahwa $O$ terisoprenilasi terikat di C-8. Berdasarkan analisis spektrum HMBC tersebut maka disimpulkan bahwa senyawa $\mathbf{1}$ adalah senyawa imperatorin [12]. Korelasi antara sinyal proton dengan sinyal karbon dalam dua atau tiga ikatan pada spektrum HMBC yang utama untuk mendukung struktur senyawa imperatorin hasil isolasi dapat dilihat pada Tabel 1 dan Gambar 2.

Tabel 1. Data spektrum NMR senyawa imperatorin (1) dan isopimpinelin (2) dalam $\mathrm{CDCl}_{3}$

\begin{tabular}{|c|c|c|c|c|c|c|}
\hline No.C & $\begin{array}{l}\delta_{\mathrm{H}}(\mathrm{mult}, J \\
\text { dalam Hz) }\end{array}$ & $\boldsymbol{\delta}_{\mathrm{C}}$ & HMBC & $\begin{array}{l}\delta_{\mathrm{H}}(\mathrm{mult}, \boldsymbol{J} \\
\text { dalam Hz) }\end{array}$ & $\boldsymbol{\delta}_{\mathrm{C}}$ & HMBC \\
\hline 1 & - & - & - & - & - & - \\
\hline 2 & - & 160,6 & - & - & 160,6 & - \\
\hline 3 & $6,34(d, 9,6)$ & 114,6 & $\mathrm{C}-2 ; \mathrm{C}-10$ & $6,26(d, 9,8)$ & 112,8 & C-2; C-10 \\
\hline 4 & $7,75(d, 9,6)$ & 144,5 & C-2; C-5; C-9 & $8,10(d, 9,8)$ & 139,5 & C-2; C-5; C-9 \\
\hline 5 & $7,34(s)$ & 113,2 & C-7; C-9; C-3' & - & 128,2 & - \\
\hline 6 & - & 125,9 & - & - & 114,8 & - \\
\hline 7 & - & 148,6 & - & - & 150,0 & - \\
\hline 8 & - & 131,6 & - & - & 144,3 & - \\
\hline 9 & - & 143,8 & - & - & 143,7 & - \\
\hline 10 & - & 116,5 & - & - & 107,6 & - \\
\hline 1 ' & - & - & - & - & - & - \\
\hline $2^{\prime}$ & $7,67(d, 2,2)$ & 146,7 & C-6; C-7; C-3' & $7,61(d, 2,3)$ & 145,2 & $\begin{array}{l}\text { C-6; C-7; C- } \\
3,\end{array}$ \\
\hline $3^{\prime}$ & $6,79(d, 2,2)$ & 106,8 & C-6; C-7; C-2' & $6,99(d, 2,3)$ & 105,2 & $\begin{array}{l}\mathrm{C}-6 ; \mathrm{C}-7 ; \mathrm{C}- \\
2\end{array}$ \\
\hline 1 ', & $4,98(d, 7,2)$ & 70,1 & C-8; C-2"'; C-3"' & - & - & \\
\hline 2, & $5,59(t, 6,2)$ & 119,8 & $\begin{array}{l}\mathrm{C}-3^{\prime \prime} ; \mathrm{C}-4 \text { ', } \\
5, \text { C- }\end{array}$ & - & - & \\
\hline
\end{tabular}




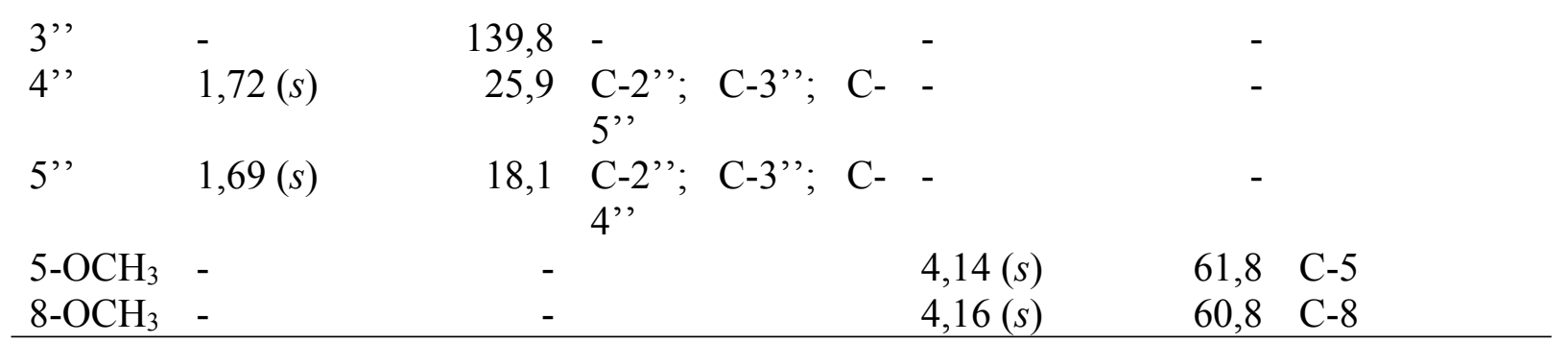

Isopimpinelin (2) berwujud padatan kuning dengan titik leleh t.1.151-152 ${ }^{\circ}$ C. Spektrum HRESIMS memperlihatkan ion kuasimolekul positif $[\mathrm{M}+\mathrm{H}]^{+}$pada $\mathrm{m} / \mathrm{z} 247,2191$ yang sesuai dengan rumus molekul $\mathrm{C}_{13} \mathrm{H}_{10} \mathrm{O}_{5}$. Spektrum UV senyawa 2 mirip dengan senyawa 1 yakni pada $\lambda_{\text {maks }}(\log \varepsilon)$ : 223 (4,20); 241 (4,00); $248(4,00)$; 268 (4,09); 311 (3,91). Spektrum ${ }^{1} \mathrm{H}-\mathrm{NMR}$ (Tabel-1)senyawa 2 mempunyai pola yang sama dengan senyawa 1, Perbedaan utama pada atom C-5 dan C-8 senyawa 2 mempunyai gugus metoksi sedangkan senyawa 1 mempunyai gugus $O$-isoprenil pada C-8. . Spektrum ${ }^{13} \mathrm{C}-\mathrm{NMR}$ (Tabel-1) senyawa 2 dalam memperlihatkan 13 sinyal atom karbon yang terpisah secara sempurna. Penempatan kedua gugus metoksi ditetapkan berdasarkan analisis spektrum HMQC dan HMBC. Sinyal proton pada $\delta_{\mathrm{H}} 8,10(\mathrm{H}-4)$ merupakan kunci penempatan gugus metoksi. Berdasarkan analisis pada spektrum HMBC sinyal proton $\delta_{\mathrm{H}} 8,10(\mathrm{H}-4)$ berkorelasi dengan dua sinyal karbon oksiaril pada $\delta_{\mathrm{C}} 143,7$ (C-9) dan $\delta_{\mathrm{C}} 128,2(\mathrm{C}-5)$ serta satu sinyal karbon karbonil lakton pada $\delta_{\mathrm{C}} 160,6$ (C-2). Sinyal proton metoksi pada $\delta_{\mathrm{H}} 4,14$ memperlihatkan korelasi dengan sinyal karbon oksiaril pada $\delta_{\mathrm{C}}$ 128,2 (C-5) yang menunjukkan salah satu metoksi terikat di C-5. Dengan demikian gugus metoksi yang lain terikat di C-8. Berdasarkan analisis spektrum HMBC tersebut maka disimpulkan bahwa senyawa 2 adalah senyawa isopimpinelin [13]. Korelasi antara sinyal proton dengan sinyal karbon dalam dua atau tiga ikatan pada spektrum HMBC yang utama untuk mendukung struktur senyawa isopimpinelin hasil isolasi dapat dilihat pada Tabel-1 dan Gambar-2.

Kantin-6-on (3) berwujud padatan kuning muda dengan titik leleh t.l. 162-164 ${ }^{\circ} \mathrm{C}$ dan positif dengan pereaksi Dragendorf. Spektrum HRESIMS senyawa $\mathbf{3}$ memperlihatkan ion kuasimolekul positif $[\mathrm{M}+\mathrm{H}]^{+}$pada $\mathrm{m} / z 221,0716$ yang sesuai dengan rumus molekul $\mathrm{C}_{14} \mathrm{H}_{9} \mathrm{~N}_{2} \mathrm{O}$. Spektrum UV senyawa $\mathbf{3}$ dalam $\mathrm{MeOH}$ memperlihatkan serapan maksimum pada $\lambda$ maks (log $\varepsilon): 229(3,85) ; 251(3,68) ; 259(3,67) ; 268$
$(3,64) ; 299(3,48) ; 346(3,49) ; 361(3,69)$ dan 379 $(3,65)$. Spektrum IR senyawa 3 dalam $\mathrm{KBr}$ memperlihatkan pita serapan pada $v_{\text {maks }}: 1672$ $(\mathrm{C}=\mathrm{O}$ amida terkonyugasi $), 1633(\mathrm{C}=\mathrm{C}$ alkena $)$; 1600-1434 ( $\mathrm{C}=\mathrm{C}$ aromatik). Spektrum ${ }^{1} \mathrm{H}-\mathrm{NMR}$ senyawa 3 (400 MHz, Tabel-2) dalam $\mathrm{CDCl}_{3}$ memperlihatkan empat buah sinyal proton aromatik 1,2-disubstitusi pada $\delta_{\mathrm{H}} 8,62(1 \mathrm{H}, d, J=$ $8,2 \mathrm{~Hz}, \mathrm{H}-8), \delta_{\mathrm{H}} 8,06(1 \mathrm{H}, d, J=8,2 \mathrm{~Hz}, \mathrm{H}-11)$, $\delta_{\mathrm{H}} 7,68(1 \mathrm{H}, d t, J=8,2 ; 1,1 \mathrm{~Hz}, \mathrm{H}-9)$ dan $\delta_{\mathrm{H}} 7,50$ $(1 \mathrm{H}, d t, J=8,2 ; 1,1 \mathrm{~Hz}, \mathrm{H}-10)$. Analisis spektrum ${ }^{1} \mathrm{H}-\mathrm{NMR}$ juga memperlihatkan sepasang sinyal doublet orto inti aromatik lainnya $(J=5,0 \mathrm{~Hz})$ pada $\delta_{\mathrm{H}} 8,79(\mathrm{H}-2)$ dan 7,92 $(\mathrm{H}-1)$ serta sepasang sinyal proton $c i s$ vinilik $(J=9,8 \mathrm{~Hz})$ pada $\delta_{\mathrm{H}} 7,99$ (H-4) dan 6,96 (H-5). Analisis spektrum ${ }^{13} \mathrm{C}$ NMR senyawa 3 (Tabel-2) memperlihatkan 14 sinyal atom karbon yang terpisah dan posisi karbon telah dikonfirmasikan dengan spektrum HMQC dan HMBC. Sinyal proton aromatik deshielding pada $\delta_{\mathrm{H}} 8,62(\mathrm{H}-8)$ menunjukkan korelasi dengan sinyal karbon metin pada $\delta_{C}$ 130,9 (C-9), dua sinyal karbon kuarterner pada $\delta_{C}$ $124,4(\mathrm{C}-12)$ dan $\delta_{\mathrm{C}} 139,5$ (C-13) dari struktur indol. Sinyal proton aromatik piridin pada $\delta_{\mathrm{H}} 7,92$ (H-1) menunjukkan korelasi dengan sinyal karbon metin pada $\delta_{\mathrm{C}} 145,9(\mathrm{C}-2)$ inti piridin dan dua sinyal karbon kuarterner pada $\delta_{\mathrm{C}} 124,4$ (C-12) dan $\delta_{\mathrm{C}} 132,1$ (C-15) struktur indol. Sinyal proton deshielding piridin pada $\delta_{\mathrm{H}} 8,79(\mathrm{H}-2)$ berkorelasi dengan sinyal karbon metin pada $\delta_{\mathrm{C}} 116,5$ (C-1) piridin , sinyal karbon kuarterner piridin pada $\delta_{C}$ 136,2 (C-16) dan sinyal karbon kuarterner indol pada $\delta_{C} 130,3(\mathrm{C}-14)$ indol. Sinyal proton cis vinilk pada $\delta_{\mathrm{H}} 7,99(\mathrm{H}-4)$ berkorelasi dengan sinyal karbon karbonil pada $\delta_{\mathrm{C}} 159,6$ (C-6) dan sinyal karbon kuarterner cincin indol pada $\delta_{C}$ 132,1 (C-15). Sinyal proton cis vinilk pada $\delta_{\mathrm{H}}$ 6,96 (H-5) memperlihatkan korelasi dengan sinyal karbon karbonil pada $\delta_{\mathrm{C}} 159,6$ (C-6) dan sinyal karbon kuarterner piridin pada $\delta_{\mathrm{C}} 136,2$ (C-16). Berdasarkan analisis spektrum HMBC tersebut maka disimpulkan bahwa senyawa $\mathbf{3}$ adalah senyawa kantin-6-on [14. Korelasi antara sinyal proton dengan sinyal karbon dalam dua 
atau tiga ikatan pada spektrum HMBC yang utama untuk mendukung struktur senyawa kantin-6-on dapat dilihat pada Tabel 2 dan Gambar 2.

Tabel 2. Data spektrum ${ }^{1} \mathrm{H}$ dan ${ }^{13} \mathrm{C}-\mathrm{NMR}$ senyawa kantin-6-on (3) dalam $\mathrm{CDCl}_{3}$

\begin{tabular}{|c|c|c|c|c|c|}
\hline \multirow{2}{*}{ No. C } & \multicolumn{3}{|c|}{ Kantin-6-on hasil isolasi } & \multicolumn{2}{|c|}{ Kantin-6-on pembanding } \\
\hline & $\delta_{\mathrm{H}}(\mathrm{mult}, \boldsymbol{J} \mathrm{Hz})$ & $\delta_{\mathrm{C}}$ & HMBC & $\delta_{\mathrm{H}}(\mathrm{mult}, J \mathrm{~Hz})$ & $\delta_{C}$ \\
\hline 1 & $7,92(d, 5,0)$ & 116,5 & $\mathrm{C}-2 ; \mathrm{C}-12 ; \mathrm{C}-15$ & $7,80(d, 5,0)$ & 116,1 \\
\hline 2 & $8,79(d, 5,0)$ & 145,9 & C-1; C-14; C-16 & $8,70(d, 5,0)$ & 145,6 \\
\hline 4 & $7,99(d, 9,8)$ & 139,7 & $\mathrm{C}-6 ; \mathrm{C}-15$ & $7,90(d, 9,8)$ & 139,3 \\
\hline 5 & $6,96(d, 9,8)$ & 129,0 & C-6; C-16 & $6,88(d, 9,8)$ & 128,7 \\
\hline 6 & - & 159,6 & - & - & 159,2 \\
\hline 8 & $8,62(d, 8,2)$ & 117,3 & C-9; C-12; C-13 & $8,50(d, 8,0)$ & 117,0 \\
\hline 9 & $7,68(d t, 8,2 ; 1,1)$ & 130,9 & C-8; C-11; C-13 & $7,59(t, 8,0)$ & 130,6 \\
\hline 10 & $7,50(d t, 8,2 ; 1,1)$ & 125,7 & C-8; C-9; C-12 & $7,42(t, 8,0)$ & 125,4 \\
\hline 11 & $8,06(d, 8,2)$ & 122,7 & C-9; C-13 & $7,98(d, 8,0)$ & 122,4 \\
\hline 12 & - & 124,4 & - & - & 124,1 \\
\hline 13 & - & 139,5 & - & - & 139,1 \\
\hline 14 & - & 130,3 & - & - & 129,9 \\
\hline 15 & - & 132,1 & - & - & 131,7 \\
\hline 16 & - & 136,2 & - & - & 135,9 \\
\hline
\end{tabular}

Uji aktivitas antioksidan senyawa 1-3 terhadap radikal DPPH memperlihatkan nilai konsentrasi daya hambat $\mathrm{IC}_{50}$ sebesar $3,90 \pm 0,40$, $206,10 \pm 2,15$ dan $400,80 \pm 5,30 \mu \mathrm{g} / \mathrm{ml}$. Asam askorbat sebagai kontrol positif memperlihatkan nilai $\mathrm{IC}_{50}$ sebesar $54,80 \pm 1,30 \mu \mathrm{g} / \mathrm{ml}$. Senyawa imperatorin (1) memiliki aktivitas antoksidan yang kuat sedangkan senyawa isopimpinelin (2)
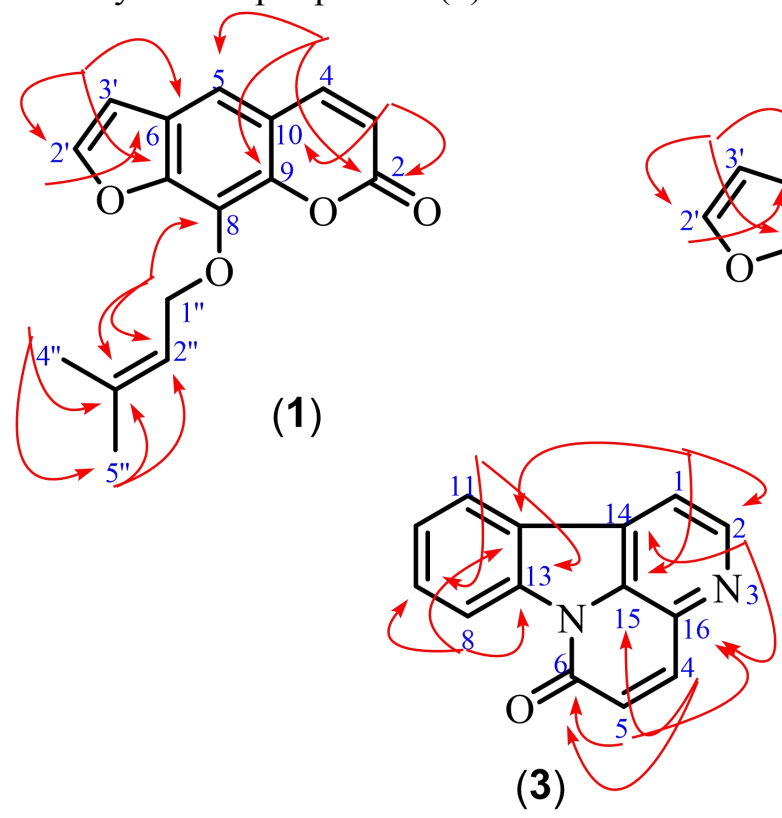

dan kantin-6-on (3) memiliki aktivitas antioksidan yang moderat. Senyawa imperatorin memperlihatkan aktivitas yang kuat dibandingkan dengan asam askorbat (kontrol positif). Senyawa $\mathbf{1}$ dan $\mathbf{2}$ mempunyai kerangka kumarin yang sama, Adanya gugus $O$-isoprenil meningkatkan aktivitas antioksidan dibanding metokasi pada senyawa $\mathbf{2}$.

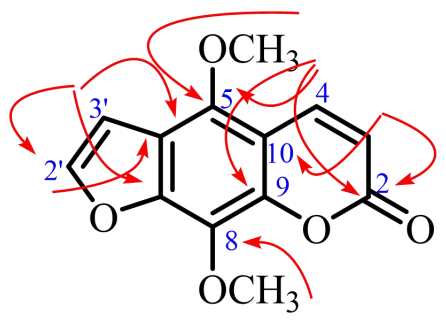

(2)

Gambar 2. Korelasi HMBC yang utama pada senyawa 1-3

\section{KESIMPULAN}

Dua senyawa kumarin yakni imperatorin (1), senyawa isopimpinelin (2) dan satu senyawa alkaloid yakni kantin-6-on (3) telah berhasil diisolasi dari kulit batang Z. ovalifolium. Senyawa imperatorin (1) memperlihatkan aktivitas aktivitas antioksidan yang kuat sedangkan isopimpinelin (2) kantin-6-on (3) 
memiliki aktivitas moderat. Ketiga senyawa hasil isolasi diharapkan dapat dimanfaatkan dalam dunia kesehatan.

\section{UCAPAN TERIMAKASIH}

Ucapan terimakasih disampaikan kepada Ismail Rachman, staff Botani, LIPI Biologi, Cibinong, Bogor atas voucher dan identifikasi tumbuhan.

\section{DAFTAR PUSTAKA}

[1] Heyne, K., (1987). Tumbuhan Berguna Indonesia, Jilid II, Badan Penelitian dan Pengembangan Kehutanan, Departemen Kesehatan Republik Indonesia, Jakarta.

[2] Negi, J.S., Bisht, V.K., Bhandari, A.K., Singh, P., Sundriyal, R.C., (2011), Chemical constituents and biological activities of the genus Zanthoxylum: A review, African J.Pure and Applied Chem., 5(12), 412-416.

[3] Tjahjandarie, T.S., Tanjung, M., (2015). Lead compound antimalaria dan antioksidan senyawa alkaloid, flavonoid, dan kumarin dari Limonia accidisima L.. Laporan Akhir Penelitian Unggulan Perguruan Tinggi, Universitas Airlangga. 1-45.

[4] Tanjung, M., Saputri, R.D., Tjahjandarie, T.S., (2017b). 4-Methoxy-3-(3-methylbut-2en-1-yl)-7-((3-methylbut-2-en-1-yl)oxy) quinolin-2(1H)-one from Melicope moluccana T.G. Hartley. Molbank. M939. 2, $1-5$.

[5] Marliana, E., Tjahjandarie, T.S., Tanjung, M., (2016). Aktivitas antioksidan senyawa flavonoid dari Macaranga pearsonii Merr. $J$. Kimia Mulawarman. 13(2), 97-100.

[6] Tanjung, M., Saputri, R.D., Tjahjandarie, T.S., (2014). Antioxidant activity of two isomeric benzoxepin derivatives from the stem bark of Bauhinia aculeata L. J. Chem. Pharm. Res. 6, 705-708.

[7] Tjahjandarie, T.S.; Saputri, R.D.; Tanjung, M. (2017). 5,9,11-Trihydroxy-2,2-dimethyl3-(2-methylbut-3-en-2-yl)pyrano[2,3-a] xanthen-12(2H)-one from the stem bark of Calophyllum tetrapterum Miq. Molbank. M936. 1, 1-5.
[8] Tanjung, M., Tjahjandarie, T.S., Sentosa, M.H., (2013). Antioxidant and cytotoxic agent from the rhizomes of Kaempferia pandurata. Asian Pacific J. Tropical Disease. 3(5), 401-404.

[9] Tanjung, M.; Rachmadiarti, F.; Saputri, R.D.; Tjahjandarie, T.S. Mesucalophylloidin, a new isoprenylated 4-phenylcoumarin from Mesua calophylloides (Ridl.) Kosterm. Nat.Prod. Res (2017a), 1-6, http://dx.doi.org/10.1080/14786419.2017.13 78215

[10] Tanjung, M; Fitriati, F.F.; Saputri, D.S; Tjahjandarie, T.S. Antimalarial and antioxidant of isoprenylated coumarins from the stem bark of Mesua borneensis L. (2016), J Biol Active Prod from Nature. 6, 95-100.

[11] Tjahjandarie, T.S.; Saputri, R.D.; Tanjung, M. (2016). Oxygeranylated coumarins from the root of Limonia accidisima $\mathrm{L}$. and their DPPH radical scavenging activity.Der Pharmacia Lettre. 8(20), 33-36.

[12] Muller, M., Byres, M., Jaspars, M., Kumarasamy, Y., Middleton, M., Nahar, L., Shoeb, M., Sarker, S.D., (2004), 2D NMR spectroscopic analyses of archangelicin from the seeds of Angelica archangelica, Acta Pharm, 54, 277-285.

[13] Siridechakorn, I., Laphookhieo, S., (2012), Chemical constituens from Feronia limonia roots, Chem. Nat. Compd, 48 (2), 308-309

[14] Soriano-Agaton, F., Lagoutte, D., Poupon, E., Roblot, F., Fournet, A.,Gantier, J., Hocquemiller, R., (2005), Extraction, hemisynthesis, and of canthine-6-one analogues. Evaluation of their antifungal activities. J. Nat. Prod, 68(11), 1581-1587. 